\title{
Editorial: Darwin Year
}

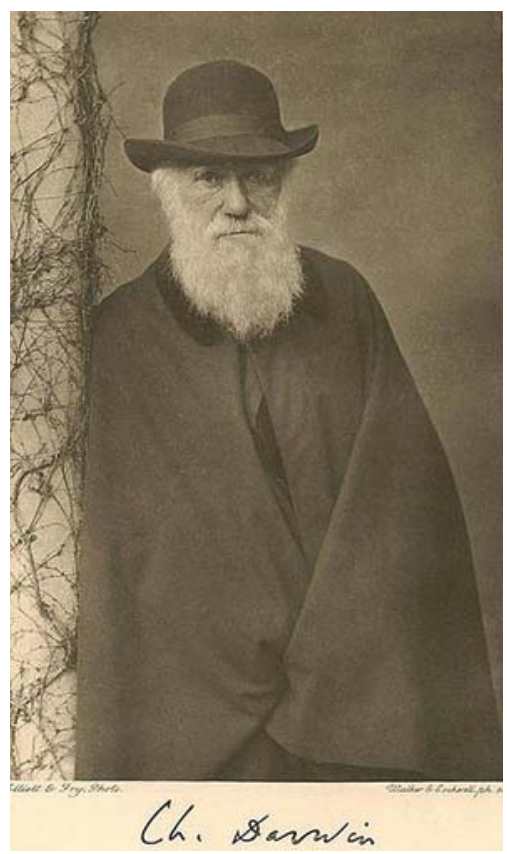

The year 2009 marks 200 years since Charles Darwin's birth, and 150 years since the publication of his classic, On the Origin of Species. One would have to be rather oblivious not to be aware of this double anniversary year, for throughout the world there are celebrations, symposia, lecture series, essays and books marking the occasion. The JHB has had a special relationship to Darwin and the Origin. Since journal's inception in 1968 it has published extensively on Darwin and on Darwinian evolution. Although Everett Mendelsohn's Editorial Forward to the first issue of the journal (Spring, 1968) stated that the journal would welcome articles from all periods and special emphasis would be paid to the last half-century, even a casual glance at the early volumes reveals considerable attention to Darwin and Darwinian evolution. And for good reason: the theory of evolution is the central 
organizing theory of the life sciences; as Dobzhansky phrased it, "nothing in biology makes sense except in the light of evolution."1 During the first 30 years, the JHB published roughly 40 articles per decade on Darwin or Darwinian evolution. Many of these have become classics that reveal Darwin's intellectual development as well as the major changes that characterize the history of evolutionary thought after him. There has been a drop over the past 10 years in the number of articles on these subjects - about 25 articles have been published in that period which partly reflects shifts in the overall perspective of our field - more attention to social context of science, less on intellectual history, and increased research on contemporary topics in the life sciences, especially molecular and experimental biology. The percentage of effort devoted to Darwin and the subsequent history of his theory, mirrors the discipline of the history of biology. Darwin and Darwinian evolution, nonetheless, continue to attract significant scholarly effort, and if the JHB has not become the Journal of Darwinian Studies, it still receives many submissions on the topics and continues to publish regularly on them.

For this anniversary year, there will be a number of interesting Darwinian articles, and, in addition, we have asked some prominent historians to contribute essays in our "Documents and Essay" section. We shall have an essay in each of the next issues of this volume that explore important subjects: our current knowledge about Darwin's life, the context of his theory, and the development of our modern theory. And, don't forget to toast Charles on February 12, and the Origin on November 24.

Paul Farber

Editor

1 Theodosius Dobzhansky, "Biology, Molecular and Organismic", American Zoologist, 4 (4) (1964): 449. He later published a famous article with the title, "Nothing in Biology Makes Sense Except in the Light of Evolution", American Biology Teacher, 35 (1973): 125-129. 